\title{
A CAPOEIRA COMO INSTRUMENTO E RECURSO TERAPÊUTICO PARA PESSOAS COM SOFRIMENTO PSÍQUICO
}

\author{
Fabio Veronesi $i^{1}$ \\ Carmen Leontina Ojeda Ocampo Moré ${ }^{2}$
}

\section{RESUMO}

Tendo como base os princípios da reforma psiquiátrica, novos profissionais e recursos terapêuticos entraram em cena para compor o trabalho das equipes de saúde, visando construir outras possibilidades além dos tratamentos médico-centrados. O objetivo deste artigo é relatar a experiência de extensão universitária de utilização da Capoeira de Angola como instrumento e recurso terapêutico no tratamento de pessoas com sofrimento psíquico, usuárias de psicotrópicos, que buscam auxílio nos Centros de Apoio Psicossocial. O artigo também apresenta, dentro da abordagem da Psicologia Somática, alguns dos recursos que a Capoeira foi capaz de oferecer enquanto instrumento psicoterapêutico.

Palavras-chave: Capoeira. Saúde mental. Psicologia somática.

\footnotetext{
${ }^{1}$ Acadêmico do Curso de Psicologia da UFSC. facaverna@gmail.com

${ }^{2}$ Graduada em Psicologia pela Universidade Federal de Santa Catarina (UFSC), mestre em Psicologia Clínica pela Pontifícia Universidade Católica de São Paulo (PUC-SP) e doutora em Psicologia Clínica também pela PUC-SP. Professora associada I da UFSC. Desde 2002, atua como Preceptora do Programa de Residência Integrada Multidisciplinar em Saúde da Família junto ao Departamento de Saúde Pública da UFSC. carmenloom@gmail.com
} 


\title{
CAPOEIRA AS A TOOL AND THERAPEUTIC RESOURCE FOR PEOPLE WITH PSYCHIC INJURY
}

\begin{abstract}
Based on the principles of psychiatric reform, new resources and professional therapeutic stepped in to compose the work of teams of health, aiming to construct other possible reatments besides the doctor-centered. The aim of this paper is to report the experience of university extension for the use of Capoeira Angola as a tool and therapeutic agent in treating people with psychological distress, users of psychotropic drugs, seeking assistance at the Centers for Psychosocial Support. The paper also provides, within the approach of Somatic Psychology, some of the features that Capoeira was able to offer as a psychotherapeutic tool.
\end{abstract}

Keywords: Capoeira. Mental health. Psychology somatic.

\section{INTRODUÇÃO}

A análise das políticas de Saúde Mental evidencia, de forma sistemática, uma forma de exercício da Psiquiatria baseada em processos de isolamento, segregação, exclusão social e anulação dos direitos civis - tratamento historicamente dado aos "loucos" isolados em grandes manicômios distantes dos centros urbanos. Esse caráter segregador começou a ser questionado no início do século XX, através de críticas e reivindicações que geraram o movimento da Reforma Psiquiátrica, o qual possibilitou a transformação efetiva da intervenção do Estado sobre a concepção de doença mental e tratamento.

Esse movimento teve como principal referência os trabalhos de Franco Basaglia, na década de 60, na Itália, onde surgiram as comunidades terapêuticas com equipes multidisciplinares. Esse tipo de experiência e, principalmente, a proposta de tornar protagonistas as pessoas portadoras de sofrimento psíquico, foi sendo paulatinamente incorporada em âmbito mundial, avançando decisivamente na desconstrução do aparato manicomial e na ampliação dos direitos civis das pessoas com esse tipo de sofrimento. (ROTELLI; AMARANTE, 1992) 
No Brasil, a proposta da Reforma Psiquiátrica, na década de 70, recebeu um importante impulso com a Reforma Sanitária Brasileira, através da aprovação de leis e portarias que deram início à desinstitucionalização de uma população que se encontrava sujeita a condições precárias de vida, sem direitos e sem dignidade. (MARCHI, 2005)

Isto fica explícito no relatório da III Conferência Nacional de Saúde, que afirma:

as políticas de saúde mental devem ter como pressupostos básicos a inclusão social e a habilitação da sociedade para conviver com a diferença. É de fundamental importância a integração desta política com as outras políticas sociais [...] visando garantir o exercício pleno da cidadania [...] A efetivação da Reforma Psiquiátrica requer agilidade no processo de superação dos hospitais psiquiátricos e a concomitante criação da rede substitutiva que garanta o cuidado, a inclusão social e a emancipação das pessoas portadoras de sofrimento psíquico. (RELATÓRIO III CONFERÊNCIA DE SAÚDE, 2002, p. 23-24)

Também a III Conferência (2002, p. 24) estabelece que "as novas modalidades assistenciais substitutivas desenvolvam práticas pautadas em relações que potencializem a subjetividade, a autoestima, a autonomia e a cidadania e busquem superar a relação de tutela e as possibilidades de reprodução de institucionalização e/ou cronificação".

As bases dessa reforma psiquiátrica têm construído a produção de uma clínica ampliada, que transcende a oferta exclusivamente medicalizante, apresentando novos modos de cuidado que operem na produção de subjetividade e provoquem novos modos de existência, que sejam construtores de sujeitos em transformação, atuando na desconstrução de estigmas sociais acerca de saúde/doença mental, na perspectiva de um novo paradigma clínico em saúde mental (ALVES; SEMINOTTI, 2006)

Essa tentativa mundial de quebra do modelo de saúde mental centrado no hospital psiquiátrico, que há décadas já vem ocorrendo em países como Inglaterra, França, Estados Unidos e Itália, encontra sua face brasileira na experiência dos CAPS - Centro de Apoio Psicossocial espalhados por todo país. Com o objetivo de construir metodologias para promoção da saúde integral - física e mental - através da introdução de hábitos saudáveis no cotidiano, bem como de encontrar os melhores meios de reintegração dos pacientes à sociedade, os CAPS têm baseado suas intervenções dentro do modelo conhecido como "oficinas terapêuticas", que se caracterizam pelo objetivo de potencializar as ações dos usuários, no sentido de que possam arregimentar e redirecionar seus desejos, num movimento de produção diária. Assim, as oficinas são expressivas, didáticas, criativas, com enfoque corporal etc. (PAIXÃO, 2009)

É nesse contexto, pelos diversos recursos terapêuticos que oferece associada à forte 
presença na cultura brasileira, que a Capoeira está presente em oficinas de vários CAPS em todo o Brasil.

Este artigo retrata algo dessa experiência nacional através do relato de um graduando em Psicologia / professor de Capoeira que durante um ano promoveu oficinas semanais de capoeira para os usuários de dois Centros de Apoio Psicossocial da Secretaria de Saúde do município de Florianópolis - o CAPS Ponta do Coral e o CAPSi (infantil). Tal relato quer destacar, além da experiência em si, algo dos recursos terapêuticos que a Capoeira foi capaz de oferecer enquanto técnica, dentro uma visão baseada na Psicologia Somática.

\subsection{A CAPOEIRA DE ANGOLA: SUAS PECULIARIDADES}

A Capoeira de Angola é também chamada de Capoeira-mãe, por ser o ritual que, no século XXI, preserva a música, o canto, a ética, a ludicidade, a "mandinga" e a movimentação do ritual de capoeira que era praticado no início do século XX, e que já trazia, nessa época, a bagagem de trezentos anos de história.

O termo "de Angola" passou a ser usual para distinguir a capoeira tradicional da variante criada por mestre Bimba,em 1932 - a chamada Capoeira Regional que modificou o ritual da capoeira tradicional, misturando conteúdos de artes marciais.

Atualmente começa a surgir uma variante da Capoeira Regional chamada de Capoeira Contemporânea, na qual o "agarra-agarra" do Jiu-Jitsu quebrou uma antiga tradição ética da capoeiragem, de não agarrar o companheiro durante o jogo. Diante desse quadro, a Capoeira Regional começou uma luta para preservar o seu ritual de setenta anos de história e a Capoeira de Angola, para preservar o seu de quatrocentos.

Apesar de todos esses rituais poderem ser definidos como capoeira, há diferenças fundamentais na prática, na ética, na proximidade dos corpos, na cadência do jogo, na musicalidade, na vestimenta etc. que os distinguem. Tais distinções precisam ser ressaltadas porque dizem respeito à utilização da capoeira como instrumento terapêutico para usuários dos CAPS. Considera-se que as peculiaridades da Capoeira de Angola proporcionam melhores recursos para liberdade criativa de movimentos, buscam um jogo com maior diálogo corporal, menor competição e maior ludicidade.

Tais características foram ao encontro do principal objetivo da oficina que era promover o reconhecimento corporal através da movimentação e da ludicidade presente no universo do ritual da Capoeira de Angola, de pacientes usuários do CAPS e CAPSi, com intuito de diminuir tanto os efeitos do uso contínuo da medicação psiquiátrica, como também favorecer e ampliar o 
processo de socialização dos usuários. Nesse contexto, o objetivo do presente artigo é relatar a experiência realizada nas oficinas, bem como apresentar a Capoeira, enquanto técnica terapêutica, e analisar os diversos recursos que ela oferece nesse sentido.

\section{MATERIAL E MÉTODOS}

Utilizar a Capoeira de Angola como instrumento terapêutico para pessoas com sofrimento psíquico foi uma iniciativa dos Centros de Apoio Psicossocial adulto - CAPS Ponta do Coral - e infantil - CAPSi, da Secretaria de Saúde do município de Florianópolis, proposto por profissionais das Instituições envolvidas e que buscavam novas metodologias de acolhimento dos usuários na busca de seu protagonismo.

As equipes profissionais desses centros eram compostas por psicóloga(o)s, enfermeira(o)s, auxiliares e técnicos de enfermagem, pedagoga(o)s, neurologistas, psiquiatras, estagiária(o)s, auxiliares de serviços gerais e vigias.

Todos os usuários atendidos pelos CAPSs, após avaliação clínica realizada pela equipe, eram encaminhados para uma ou mais oficinas terapêuticas ali oferecidas, bem como para atendimento individual, familiar e medicamentoso, conforme o caso. Além da Capoeira Angola, esses centros ofereciam oficinas de trabalhos artesanais, musicais, teatrais, culinários e de manuseio da terra para os usuários de seus serviços.

As oficinas de Capoeira eram realizadas em grupo, em seções de 1 hora no CAPS Ponta do Coral (adultos) e de 45 minutos no CAPSi (infantil), ambas com periodicidade semanal. No CAPS Ponta do Coral geralmente alternavam-se semanas de trabalho com movimentação corporal e semanas de trabalho com toque de instrumentos e aprendizagem dos cantos Ladainhas e corridos da Capoeira. No CAPSi geralmente trabalhavam-se movimentação e música na mesma seção. Essas diferenças se construíram empiricamente ao longo do processo de trabalho nas oficinas, em busca de melhor suprir as necessidades dos usuários. Apesar de ambos serem denominados "usuários", as exigências, as características e as necessidades dos usuários do CAPS Ponta do Coral eram muito diferentes das dos usuários do CAPSi.

O CAPS Ponta do Coral atendia a adultos que estavam, em geral, sob constante tratamento quimioterápico, apresentavam dificuldade crônica de mobilização e expressividade limitada, queixando-se constantemente de dores no corpo. Necessitavam de aquecimento e alongamento lentos e cuidadosos para que seus corpos pudessem explorar os movimentos diferentes dos normais do cotidiano, presentes na capoeira - como os movimentos rasteiros ou 
feitos de cabeça para baixo. Dessa forma a orientação para os participantes era para que não forçassem seus corpos, mas que os percebessem na intenção do movimento. É importante lembrar que o objetivo da oficina não era formar capoeiristas, mas sim trabalhar os movimentos de capoeira como possibilidade de expressão corporal. Seus níveis de consciência, expressos nas suas fugas do "aqui-agora" e dificuldades de relação com o outro se expressavam principalmente pela mecanicidade ou ausência de movimento, pela imobilidade do olhar e pelo silêncio.

As crianças do CAPSi, em geral, fugiam do "aqui-agora" pela via da hiperatividade, pela inconstância do olhar e pelo grito. Expressavam suas dificuldades de socialização, de contato com o outro, através de agressões físicas. Contrariavam explicitamente, quer dizer com atitudes contrárias a todos os tipos de propostas que eram apresentados em tom de ordem, obrigação ou regra. Sua atenção e disposição estavam associadas à curiosidade e ao desafio que lhes traziam as propostas de movimento. Exploravam os movimentos propostos e rapidamente já criavam novas possibilidades. Assim, uma boa estratégia metodológica foi criar sequências de movimento trazendo como proposta de movimentação coletiva os movimentos que as crianças inventavam individualmente em suas explorações pessoais. Isso só foi possível devido à intensa criatividade e capacidade corporal dos usuários. O tempo menor das sessões se devia ao tempo menor de saturação com relação aos adultos. Explorar movimentações corporais e música numa mesma seção foi uma forma de trazer novidades para mantê-los interessados.

\section{RESULTADOS E ANÁLISES}

Nos trabalhos de movimentação corporal buscava-se a alternância entre aprender movimentos individualmente e depois utilizá-los em diálogos corporais com o outro, no jogo pergunta/resposta que acontece nos ataques/defesas da capoeira. Primeiro o usuário trabalhava individualmente a capacidade de seu próprio corpo executar um movimento, dos muitos existentes no repertório da Capoeira, que lhe era apresentado pelo oficineiro-capoeirista. Nesse momento, o usuário desenvolvia a capacidade de aprendizagem por imitação somática observação do movimento do outro e tentativa de repeti-lo em seu próprio corpo.

Essa concepção de trabalho somático por "espelhamento" era utilizada tanto na apresentação do movimento, como também na evolução do seu aprendizado pelo usuário. Primeiro o professor-oficineiro mostrava como deveria ser o movimento, esperando que o aluno o imitasse. Depois era o professor que imitava o aluno, quando queria corrigi-lo, fazendo com seu próprio corpo o movimento que o aluno fez a partir daquele que ele tentou the ensinar. 
Isso levava o professor a entender as dificuldades do usuário-aluno em executar o movimento proposto. Também mostrava ao usuário que o corpo do professor podia se flexibilizar a ponto de incorporar o movimento do usuário e o convidava, assim, a também flexibilizar-se a ponto de incorporar o movimento do professor, desenvolvendo a "propriocepção" do usuário - sua capacidade de perceber a própria postura e movimento.

Essa fase também trabalhava bastante a memória somática, visto que sempre era preciso relembrar, reaprender movimentos apresentados e aprendidos em seções anteriores, na construção de novos movimentos. Finalmente essa primeira fase era marcada pela repetição e previsibilidade do movimento. Em contraponto, a segunda fase - de diálogos corporais - era marcada pela imprevisibilidade e improvisação a partir dos movimentos conhecidos. $\mathrm{O}$ movimento do outro influencia meu movimento e vice-versa. Eu respondo e pergunto, recebo resposta e nova pergunta e assim por diante. Um jogo nunca é igual a outro. Essa fase trabalhava o resgate e desenvolvimento do reflexo, da criatividade e da capacidade de socialização do usuário.

Nos trabalhos com música, explorava-se o toque da capoeira nos diferentes instrumentos que fazem parte do seu ritual: pandeiro, reco-reco, agogô, atabaque e berimbau. Os instrumentos eram revezados entre os participantes, conforme seus interesses e curiosidades. Paralelamente acontecia o trabalho com o canto. O desenvolvimento da coordenação motora acontecia não só no trabalho de sustentação do ritmo, como na busca de cantar e tocar sem perder a cadência.

No trabalho com o canto exploraram-se os papéis de "puxador" e de participantes do "coro", presentes nos "corridos" da capoeira. Responder ao coro significa repetir em conjunto frases simples em intervalos de tempo iguais, intercalados pelo tempo do puxador que canta sozinho outra estrofe e pode improvisar dentro de uma gama de possibilidades que aquele corrido permite. A repetição do coro permite que as dificuldades com o cantar sejam trabalhadas aos poucos num ambiente em que os participantes incentivam uns aos outros. Depois de aprendido o corrido por todos que respondem o coro, passou-se a alternar o papel de puxador entre os participantes. Isso permitia trabalhar as dificuldades de destacar-se em público e também a possibilidade de ouvir a voz de cada um independe das outras vozes, brincando com a improvisação e sentindo a responsabilidade de criar uma frase para o coro responder.

A produção da música era coletiva e havia necessidade de que todos tocassem no mesmo ritmo. Isso também ajudava no processo de propriocepção dos usuários. As dificuldades individuais de manter o ritmo ao tocar um instrumento estavam associadas muitas vezes, à ansiedade - que fazia acelerar o ritmo em relação aos outros, ou à distração - que levava a 
"perdê-lo". Para que uma pessoa pudesse saber se estava ou não tocando no ritmo, ela precisava prestar atenção nos outros, buscar o coletivo. Em maior ou menor grau, todos participavam em algum momento como puxadores de corridos e ajudavam a segurar o ritmo enquanto o outro cantava.

Dentro da análise dessa experiência e de acordo com o objetivo deste artigo, é fundamental apontar os recursos que a Capoeira de Angola foi capaz de oferecer como técnica terapêutica. Nesse sentido, destacam-se:

a) desenvolvimento da musicalidade: o ritmo básico da Capoeira é de fácil aprendizado e serve de "trampolim" para o aprendizado do samba e de outros ritmos brasileiros. A cultura da Capoeira é praticamente toda oral, transmitida através das "Ladainhas" e dos "corridos" - canções que contam as histórias e os ditos da capoeira. O capoeirista canta, toca e joga. Esses elementos, aprendidos separadamente e depois associados, conseguiram desenvolver nos usuários aptidões de ritmo e canto, trabalhando sobre a melhora da sua coordenação motora;

b) movimentação e expressão corporal: os movimentos de ataque e defesa da capoeira mexem com as articulações e musculatura de todo o corpo. Esse trabalho ajuda a combater o enrijecimento provocado pelo uso contínuo de psicotrópicos. Além disso, especificamente na Capoeira Angola, valoriza-se a teatralidade, ludicidade, enganação e intencionalidade na movimentação corporal, elementos que ajudam o trabalho sobre a liberação da expressividade contida;

c) efeito grouding: a repetição do movimento de ginga, que é a base de onde saem todos os outros, o constante abaixar-se/levantar-se e a variação da base de sustentação e contato com o chão pelos cincos pontos de apoio: pés, mãos e cabeça, na movimentação da capoeira, proporcionam o efeito bioenergético conhecido como grounding (aterramento), que auxilia o reequilíbrio do excesso de energia das partes altas do corpo devido intensa atividade mental, aumentando a percepção sobre o aqui-agora;

d) trabalho sobre o olhar: dentro da caracteriologia psicossomática (NAVARRO 1995), o traço psicótico está associado ao segmento ocular. No processo de crescimento humano, o momento de percepção primária do Eu acontece paralelo ao desenvolvimento da capacidade fisiológica de enxergar o outro, de reconhecer outro ser humano, que ocorre nos primeiros meses de vida extrauterina. No traço psicótico, a "quebra" do Eu primário percebe-se pela fuga do olhar. Além disso, de 
maneira geral, as dificuldades de contato com o outro estão presentes na dificuldade de troca de olhares encontrada em todos nós. A Capoeira Angola possibilita um amplo trabalho sobre o olhar por tratar-se de uma dança onde nos movimentamos buscando olhar o outro para que esse não nos pegue desprevenido com algum golpe e para que nossos próprios golpes tenham coerência. Desta forma, quando nos elevamos, abaixamos, giramos em torno do próprio eixo ou mesmo ficamos de cabeça para baixo, estamos buscando olhar a movimentação do companheiro para que se mantenha o diálogo de perguntas e respostas corporais;

e) trabalho sobre a voz: a capacidade terapêutica do exercício de cantar é amplamente reconhecida. A voz está associada à expressão. A Capoeira acrescenta a essa poderosa ferramenta a figura da "plateia" formada pelos participantes da roda. A roda de capoeira é um momento de exibição. Para se exibir a arte, se exibem os jogadores, o cantador, os tocadores. Não se trata, portanto, de somente cantar, mas também de se apresentar frente a uma plateia de ouvintes. As diversas funções dos cantadores no ritual da capoeira permitem uma escala evolutiva que vai de participante do coro, passa por puxador de corrido e chega a cantador de Ladainha. No primeiro estágio, se repetem junto com os outros, as mesmas duas ou três frases que são a resposta padrão do corrido, isso permite maior possibilidade de erro, desafino, engasgo, distração, desânimo etc., e ao mesmo tempo, dá espaço para cantar alto e forte conforme vai sentindo maior segurança para soltar a voz; a automatização da resposta despreocupa o cantador iniciante de ter que se ocupar de pensar no que cantar. No segundo estágio, assume-se o papel de quem escolhe que corrido cantar, inicia o canto sozinho, puxando a resposta do coro e responsabiliza-se por manter aquele corrido; com a experiência, pode-se partir para o segundo, terceiro, quarto corrido; o bom cantador é aquele capaz de amarrar os dizeres do corrido que ele está puxando com o momento do jogo que está acontecendo; as frases dos corridos são mais diversas do que as que o coro responde e o puxador pode improvisar frases em cima da resposta do coro. O terceiro estágio é evolução natural do segundo, a Ladainha é o canto que abre a roda ou a reinicia após qualquer intervalo - quando se trocam os integrantes da bateria, por exemplo. A Ladainha é mais longa que o corrido - ela conta uma história, um causo, louva grandes mestres e jogadores, fala de amor, de luta, da escravidão, de Palmares etc., por isso precisa ser interpretada em tom de lamento, alegria, louvação, desdém etc., conforme a história a ser contada. Há um respeito 
silencioso da plateia no momento da Ladainha. Não há coro. O cantador canta sozinho. Não há jogo, os jogadores ficam parados próximos ao cantador. No fim da Ladainha o cantador faz a Louvação, só daí entra o coro, mas o jogo ainda não começa. Ele só se inicia quando o cantador puxa o primeiro corrido. A responsabilidade do cantador que inicia uma roda é grande, ele escolhe a Ladainha, improvisa a Louvação e puxa os primeiros corridos, ou seja, tem que pensar em várias coisas enquanto toca e canta;

f) expressão da agessividade: a capoeira permite o trabalho sobre a expressão da agressividade saudável como atitude necessária diante do enfrentamento da exposição numa roda em que o jogo que acontece é o centro das atenções e na qual o elemento de luta está presente. A agressividade, que flui naturalmente num jogo lúdico e "mandingado", não se torna violência porque não se acumula. A movimentação e a ética da Capoeira Angola permitem que um golpe que foi mostrado e não aplicado seja mais bonito e apreciado do que aquele que é realmente desferido, dessa forma o oponente se torna amigo porque nos aponta nossas próprias falhas em nos defender, sem nos machucar.

g) opção estratégica de ação política: a Capoeira nasceu como expressão de liberdade de um povo escravizado. Seus cantos estão repletos de histórias sobre a escravidão, ditos e saberes populares presentes na cultura de um povo com séculos de experiência de luta contra a opressão. A movimentação corporal da Capoeira também é fruto dessa experiência. De certa forma, a Capoeira pode ser vista como uma estratégia de sobrevivência psicossomática desenvolvida contra um sistema que enxerga o ser humano como mercadoria.

Há uma clara conexão com a realidade social dos regimes político-econômicos atuais. Atualmente somos oprimidos por um sistema ideológico que, de certa forma, escraviza nossos corpos pelo processo de disciplinarização, direciona os fazeres para empresas cujos objetivos visam o lucro financeiro em primeiro lugar. A repressão moralista sobre a livre sexualidade e espontaneidade, presente nos sistemas político-ideológicos de base patriarcal, está relacionada à manutenção desses sistemas. Tal repressão é a gênese das neuroses e "patologias" psíquicas que afetam as populações a eles submetidas.

A Reforma Psiquiátrica é também um movimento que em última instância luta contra preconceitos e estigmas de exclusão social. Nesse ponto a Capoeira e a Luta Antimanicomial se encontram e tem muito a ensinar uma a outra, trocar informações e estratégias. 
A forma de defesa da Capoeira diz muito de sua estratégia de luta/sobrevivência frente à opressão: o capoeirista não corta um golpe de ataque, ao contrário ele cede, se esquiva, se encolhe e busca o chão. Ir ao chão representa humildade, é a opção daquele que sabe que não adianta "bater de frente" contra o opressor, mas é também uma armadilha para esse opressor porque cria uma falsa ideia de fragilidade. Quando as bases de apoio do corpo passam a ser as mãos, se liberam para o ataque as pernas, mais fortes e mais longas que os braços. No chão, a partir de um ângulo de visão totalmente diferente, o capoeirista encontra apoio para crescer novamente, expandir e contra-atacar ou para movimentar rasteiro, fugir e se manter vivo.

A ludicidade também é parte fundamental da estratégia de sobrevivência do capoeirista e da própria Capoeira. Durante toda sua história, o ritual da Capoeira sofreu repressão moral e policial. Conseguiu sobreviver porque se tornou lúdico, estava presente nas festas populares, encantava os jovens, agradava aos olhos do povo. Por isso a roda de capoeira é também um espetáculo e a teatralidade faz parte do diálogo corporal dos jogadores.

Os resultados alcançados com as oficinas dificilmente poderiam ser mensurados com instrumentos de medidas exatas, mas sim através de percepções do oficineiro-capoeirista, durante o acompanhamento sobre a contribuição da oficina no processo terapêutico de cada um e no coletivo dos usuários.

No CAPS adulto, o número de usuários que participavam da oficina, em média, se manteve em torno de seis, havendo bastante rotatividade entre os participantes. Ao todo, em torno de 25 usuários frequentaram a oficina durante certo tempo, mas somente um dos participantes fez a oficina durante o ano todo. Houve usuários que fizeram por seis meses, outros por três, outros por algumas semanas, outros somente por alguns dias; muitos passaram por crises que os afastaram e depois retornaram; outros nos visitavam de vez em quando para se mexer ou para cantar um pouco; outros, apesar de sempre se fazerem presentes, entravam e saiam no meio da oficina, dificilmente participando de uma seção inteira.

A oficina sempre esteve aberta para quem quisesse entrar e participar mesmo que fosse por uns momentos ou somente para assistir. Essa dinâmica é cabível no universo da capoeiragem, porque é inerente à Capoeira ser pública. Ela é aberta ao público, chama sua atenção, dá curiosidade, dá vontade de ver. Isso fez com que a oficina fosse também um espaço de encontro entre os usuários. Praticamente todos os usuários, bem como muitos funcionários, participaram pelo menos uma vez da oficina, cantando, dançando, brincando, tocando um instrumento, arriscando fazer um ou outro movimento ou, no mínimo, assistindo.

Acredita-se que esse foi o maior resultado da oficina: favorecer a socialização dos usuários do CAPS num ambiente de música, canto e dança que pertencia a todos, em que todos 
se sentiam inseridos e co-responsáveis pela produção da "festa".

Outro resultado foi a abertura de espaços de troca para os usuários que participavam das propostas de movimentação em duplas, que tiveram o efeito de integrar os participantes e que serviram inclusive para compartilhar dores e dificuldades de movimentação. Como já foi mencionado, somente um usuário participou da oficina durante todo ano. Nele, os benefícios de longo prazo se tornaram visíveis em pequenos momentos de desinibição e criatividade cinestésica, porém os avanços foram lentos, quase imperceptíveis. Acredito que o maior ganho foram os muitos momentos em que esse usuário sorriu, mostrando estar se divertindo enquanto movimentava seu corpo ou enquanto fazia música.

\section{CONSIDERAÇÕES FINAIS}

O objetivo principal deste trabalho foi apresentar a experiência com oficinas de Capoeira Angola como recurso psicoterapêutico dentro da abordagem da Psicologia Somática.

Além dos recursos apontados, defende-se a utilização da Capoeira como método terapêutico por se tratar de uma iniciativa que desenvolve "tecnologia nacional" na área de atenção à saúde psíquica, bem como uma forma de preservação e fortalecimento da cultura brasileira.

No âmbito pessoal, acredito que a maior contribuição que esse trabalho trouxe para a minha formação como psicólogo foi desenvolver paciência e perseverança, exigidos pelos desafios que se apresentaram.

Um primeiro desafio foi superar, como capoeirista, as limitações da própria Capoeira, decorrentes do fato de ela ser um ritual com seus padrões e regras. Existe muito respeito por parte dos capoeiristas na obediência ao ritual da capoeira, na sua divulgação e conservação. Nas oficinas, porém, houve um momento em que ficou claro que para servir de instrumento terapêutico, a prioridade não deveria ser dada às necessidades do ritual da capoeira, mas sim às dos usuários. O ritual passou a ser apenas um parâmetro de ressignificação para as expressões corporais dos usuários e não um padrão de exigência. Dessa forma o correto seria dizer que a oficina foi baseada em, e não de Capoeira.

O início do trabalho com as crianças apresentou tantos desafios que pensei em desistir. A constante troca de informações com a equipe de trabalho do CAPSi nasceu como resposta a esses desafios. Fora do CAPSi, buscou-se a orientação de uma pedagoga que trabalhava dança contemporânea com grupos de crianças, que deu excelentes dicas de movimentações corporais e sobre a dinâmica das aulas. Uma dica fundamental foi: "se você inicia a aula incentivando 
correria e movimentação rápida, em meia hora você terá o caos; se você inicia a aula calmamente, com movimentações tranquilas, em meia hora você terá correria".

Nesse processo de superação de dificuldades, destaca-se o processo de supervisão acadêmica, o qual mostrou, entre outras coisas, a importância da ressignificação corporal dos conteúdos trazidos pelos usuários, como forma de fugir do autoritarismo da pedagogia tradicional. Por sua vez permitiu a ressignificação dos conteúdos que apresentava e não através de respostas prontas, o que mantinha o desafio e a busca de respostas próprias. Percebeu-se especialmente como na técnica pedagógica que vinha utilizando estava trabalhando com a tradicional fórmula do "prêmio e castigo".

Constatou-se que as mudanças necessárias para a dinâmica do trabalho na oficina passavam por mudanças pessoais no desempenho do papel de professor de Capoeira, sendo necessário modificar o papel que vinha fazendo há cerca de cinco anos, cuja base foi a forma um tanto "militaresca" peculiar aos métodos pedagógicos tradicionalmente presentes na maioria dos grupos de capoeira, que só conseguiu ser eficaz com pessoas que buscavam aprender Capoeira, tinham sede de sabê-la, pagavam pelas aulas, lhe davam valor, mas que absolutamente não funcionou com psicóticos e outros usuários dos CAPS adulto, muito menos com as crianças do CAPSi.

A busca de superar essa crise instigou a nossa curiosidade, e fez questionar professores em sala de aula, buscar diálogos com pessoas que tinham experiência com crianças, com colegas que estavam estagiando etc. Construir formas de superar dificuldades foi talvez o maior aprendizado que essa experiência proporcionou tanto a "pessoa/capoeirista" e aos usuários. Acima de tudo, descobri que o vínculo afetivo que fui capaz de construir com eles foi o que mais valeu para que quisessem fazer um pouco de Capoeira comigo.

\section{REFERÊNCIAS}

ALVES, M. C.; SEMINOTTI, N. A. O Pequeno Grupo "Oficina de Capoeira" no contexto da Reforma Psiquiátrica. In: Saúde e Sociedade, Porto Alegre, v. 15, n. 1, p. 58-72, jan/abr. 2006.

AREIAS, A. O que é capoeira. São Paulo: Brasiliense, 1983

BASAGLIA, F. (Org). A Instituição negada. Rio de Janeiro: Edições Graal, 1991.

LOWEN, A. Bioenergética. 6. ed. São Paulo: Summus, 1982.

MARCHI, V. A busca da integralidade das ações nos profissionais de saúde mental: um desafio cotidiano. 2005. 126f. Dissertação (Mestrado em Psicologia) - Faculdade de 
Psicologia, Programa de Pós-graduação, Universidade Federal de Santa Catarina, Florianópolis, 2005.

NAVARRO, F. Caracteriologia pós-reichiana. São Paulo: Summus, 1995.

PAIXÃO, C. et al. Análise da prevalência dos transtornos psíquicos na região metropolitana do Recife. In: Ciência \& Saúde Coletiva, Recife, v. 14, n. 1, p. 261-266, 2009.

REICH, W. A Revolução Sexual. 8. ed. Rio de Janeiro: Ed. Guanabara, 1993.

ROTELLI, F; AMARANTE, P. Reformas Psiquiátricas na Itália e no Brasil: aspectos históricos e metodológicos. In: BEZERRA JR, B; AMARANTE, P. (Org.) Psiquiatria sem Hospício: contribuições ao estudo da reforma psiquiátrica. Rio de Janeiro: Relume- Dumará, 1992.

Brasil/MS. (2001) Lei F de Saúde Mental no 10.216 de 06/04/2001

Brasil/MS. (2002) Portaria 336/GM em 19 de fevereiro de 2002. Modelo Assistencial em Saúde Mental/Caps.

Relatório Final da III Conferência Nacional de Saúde Mental. (2002). Brasília: Conselho Nacional de Saúde/Ministério da Saúde. 